\title{
Developing the atlas of cancer in Queensland: methodological issues
}

Susanna M Cramb ${ }^{1,2^{*}}$, Kerrie L Mengersen ${ }^{2}$, Peter D Baade ${ }^{1,3}$

\begin{abstract}
Background: Achieving health equity has been identified as a major challenge, both internationally and within Australia. Inequalities in cancer outcomes are well documented, and must be quantified before they can be addressed. One method of portraying geographical variation in data uses maps. Recently we have produced thematic maps showing the geographical variation in cancer incidence and survival across Queensland, Australia. This article documents the decisions and rationale used in producing these maps, with the aim to assist others in producing chronic disease atlases.

Methods: Bayesian hierarchical models were used to produce the estimates. Justification for the cancers chosen, geographical areas used, modelling method, outcome measures mapped, production of the adjacency matrix, assessment of convergence, sensitivity analyses performed and determination of significant geographical variation is provided.
\end{abstract}

Conclusions: Although careful consideration of many issues is required, chronic disease atlases are a useful tool for assessing and quantifying geographical inequalities. In addition they help focus research efforts to investigate why the observed inequalities exist, which in turn inform advocacy, policy, support and education programs designed to reduce these inequalities.

\section{Background}

Since the 1978 declaration of Alma-Ata which highlighted the need to address inequalities in health status [1], there have been important advancements for cancer outcomes. Many developed nations have seen improvements in cancer survival, notably for colorectal cancer, breast cancer, prostate cancer, non-Hodgkin lymphoma and leukaemia $[2,3]$. Also, incidence and mortality rates for some cancers have declined [4]. However, notable inequalities in these outcomes persist, with numerous international studies reporting disparities in cancer outcomes across socioeconomic status or urban/rural categories [5-7].

Within Australia, one of the greatest recognised health challenges is achieving health equity for all [8]. Cancer patients living in rural and disadvantaged areas are generally more likely to be diagnosed with advanced cancer and have poorer survival outcomes $[9,10]$. Often these

\footnotetext{
* Correspondence: susannacramb@cancerqld.org.au

${ }^{1}$ Viertel Centre for Research in Cancer Control, Cancer Council Queensland,

Gregory Tce, Fortitude Valley, Australia

Full list of author information is available at the end of the article
}

areas have a higher prevalence of risk factors such as smoking, obesity and lower levels of physical activity $[11,12]$. Distance is also important, with cancer patients in rural areas having reduced access to cancer care services [13-15].

Inequalities need to be quantified before they can be addressed. Maps have been used to portray geographical data for a range of diseases since the mid-1800s, including cancer [16]. By providing a visual representation of cancer outcomes, geographic patterns of disease are able to be identified and effectively addressed [17]. For example, cancer mortality maps showed high mortality from oral cancer in south-eastern United States of America which led to the identification of snuff dipping as a risk factor [18]. Similarly, mammography screening efforts were intensified after finding low in-situ breast cancer incidence rates from mapped data in north-eastern Connecticut [19].

We recently developed thematic maps showing the geographical variation in cancer incidence and survival across Queensland, Australia [20]. With a population of 4.2 million [21] and covering an area of 1.9 million

Ciomed Central

(C) 2011 Cramb et al; licensee BioMed Central Ltd. This is an Open Access article distributed under the terms of the Creative Commons Attribution License (http://creativecommons.org/licenses/by/2.0), which permits unrestricted use, distribution, and reproduction in any medium, provided the original work is properly cited. 
square kilometres, Queensland has the country's most decentralized population [22] and the highest incidence of cancer [23]. As there is increasing interest in producing disease maps [24-30], it is hoped that by documenting the processes and rationale behind the many decisions made during the development of this Cancer Atlas, it may assist others seeking to produce similar types of chronic disease atlases.

\section{Methods}

Ethical approval to conduct this study was obtained from the Queensland Health - Central Office Committee Human Research Ethics Committee (HREC/09/ $\mathrm{QHC} / 25)$. Approval to extract the data was obtained from the Chief Executive Officer - Centre for Health Care Improvement, Queensland Health, under delegation by the Director-General, Queensland Health.

\section{Data sources}

The Queensland Cancer Registry (QCR) supplied deidentified data on all primary invasive cancers diagnosed among Queensland residents during 1996 to 2007. The QCR is a population-based cancer registry that maintains a record of all cases of cancer diagnosed in Queensland since 1982, with data currently available to the end of 2007 [31]. Survival status of all cancer patients is obtained through routine linkage with the (Australian) National Death Index, enabling deaths of cancer patients who die interstate to be identified. Across all cancers, 91\% of cancers registered by the Queensland Cancer Registry in 2007 were histologically verified and $1.9 \%$ were registered based on death certificate only (DCO) [31]. Cases with unknown age group ( $0.001 \%$ of all cancers) were excluded from the analyses.

Estimated resident population data grouped by age group (0-4, 5-9..., 80-84, 85+), sex, year and statistical local area (SLA) were obtained from the Australian Bureau of Statistics. To calculate the expected population mortality estimates, de-identified unit record mortality data for all causes of death for Queensland residents were also obtained from the Australian Bureau of Statistics (ABS) [32].

\section{Choice of cancers}

The Cancer Atlas described spatial variation in the leading cancers diagnosed in Queensland during the study period (Table 1). These included the (Australian) National Health Priority Area cancers of colorectal cancer, lung cancer, breast cancer, cervical cancer, prostate cancer and non-Hodgkin's lymphoma. Although a priority cancer, variation in non-melanocytic skin cancer was not assessed, since it is not routinely reported by population-based cancer registries in Australia. When a cancer was not gender specific, results were calculated for each gender. The only exception to this was breast cancer which was reported for females only due to the very small number of breast cancers diagnosed among males.

\section{Geographical areas}

SLAs were used to define the geographical areas. These are part of the Australian Standard Geographic Classification (ASGC) used by the ABS [33] and are often

Table 1 Cancers examined for geographic variation, Queensland, 1998-2007

\begin{tabular}{|c|c|c|c|}
\hline Type of cancer & ICD-03 code & Total number males diagnosed & Total number females diagnosed \\
\hline All invasive cancers & C00-C80 (excluding C44 (M805 to 811)) & 105,053 & 82,470 \\
\hline Bladder cancer & C67 & 5,034 & 1,571 \\
\hline Brain cancer & C70, C71, C72 & 1,504 & 1,067 \\
\hline Breast cancer & C50 & Not included & 22,420 \\
\hline Cervical cancer & C53 & Not applicable & 1,639 \\
\hline Colorectal cancer & C18-C20 and C218 & 13,405 & 10,871 \\
\hline Kidney cancer & C64-C66 and C68 & 3,117 & 1,883 \\
\hline Leukaemia & M980-M994 & 3,084 & 2,094 \\
\hline Lung cancer & C33-C34 & 11,152 & 5,683 \\
\hline Melanoma & C44 and M872-M879 & 13,793 & 10,110 \\
\hline Myeloma & M973 & 1,192 & 913 \\
\hline Non-Hodgkin lymphoma & M959, M967-M971 & 3,547 & 2,889 \\
\hline Oesophageal cancer & C15 & 1,464 & 639 \\
\hline Ovarian cancer & C56 & Not applicable & 2,120 \\
\hline Pancreatic cancer & $\mathrm{C} 25$ & 1,940 & 1,706 \\
\hline Prostate cancer & C61 & 25,222 & Not applicable \\
\hline Stomach cancer & $\mathrm{C} 16$ & 2,193 & 1,070 \\
\hline Thyroid cancer & $\mathrm{C} 73$ & 765 & 2,221 \\
\hline Uterine cancer & C54 & Not applicable & 3,112 \\
\hline
\end{tabular}


based on the incorporated bodies of local governments who are responsible for service provision and infrastructure at the local and regional level.

The ABS adjusts the geographical boundaries of SLAs according to changes in the population composition over time. To ensure statistical analyses referred to the same geographical area for the entire study period, all SLAs were mapped to the boundaries used for the 2006 ASGC. The mapping process was conducted within the Queensland Cancer Registry, and matched the suburb and postcode at diagnosis to the 2006 National Localities Index [34]. There were 478 SLAs in Queensland in 2006 [33].

Estimates of incidence and survival were also examined by area-level socioeconomic status and rurality. Socioeconomic status was defined using the Socioeconomic Indexes for Areas (SEIFA) Index of Relative Socioeconomic Advantage and Disadvantage (IRSAD) compiled by the ABS [35]. Queensland SLAs were ranked from the most disadvantaged to the most advantaged and then divided into quintiles, based on a variety of data items such as the percentages of: people with high income, people unemployed, households paying cheap rental, households with no car and households with broadband internet connection. Rurality was defined using the ARIA+ (Accessibility/Remoteness Index for Australia plus) classification [36], which defines remoteness on the basis of five categories: major city, inner regional, outer regional, remote and very remote. 'Remote' and 'very remote' categories were combined together. The level of remoteness is determined by road-based distance to services.

\section{Methods to generate estimates}

To produce a useful map on a small-area scale it is important to have estimates that are robust, or relatively insensitive to outliers, across small areas. If estimates are not robust, these outliers from areas which are often based on very small populations, are more likely to be disproportionately influential, and thus compromise the overall interpretation of the map.

Modelling or smoothing methods are commonly used to generate robust estimates for small geographical areas. As traditional regression models are unable to incorporate spatial correlation, approaches which enable hierarchical structure to be incorporated such as generalised linear mixed models may be used. These may be calculated using either Bayesian, multi-level, or likelihood-based models, however, Bayesian methods do not require the restrictive distributional assumptions in the other models (such as, for example, Gaussian random effects) [37]. Smoothing methods require no distributional assumptions and include interpolation methods, or non-parametric such as kernel regression, kriging and partition methods
$[38,39]$. They are generally easier and faster to perform than modelling, but a comparison of various modelling and smoothing methods suggested Bayesian models performed better than the smoothing methods [40].

Bayesian models incorporate empirical Bayes and fully Bayes methods. In both types of Bayesian models, parameters are assigned probability distributions, usually based on plausible or expected values, and termed 'priors'. Fully Bayesian methods assign second stage priors to the variance controlling this distribution ('hyperparameters'). In contrast, empirical Bayes methods estimate the hyperparameter from the distribution of the data [41]. Therefore, empirical Bayes methods give satisfactory point estimates, but are unlikely to provide accurate estimates of the associated uncertainty [42].

Fully Bayesian models are becoming increasingly common in disease mapping [43]. Advantages of Bayesian models in comparison to other methods include the ease of drawing strength from neighbouring regions so estimates are more reliable and robust, as well as providing better quantification of the uncertainty surrounding the calculated estimates $[41,44]$. Also, Bayesian methods enable structuring of more complicated models, inferences and analyses [45]. Other cancer atlases which have used fully Bayesian methods include NSW (Australia) [46] and Limburg (Belgium) [47] (Table 2).

\section{Outcome measures - what to map? Incidence estimates}

Incidence is defined as the number of new invasive cancer cases diagnosed within a given time period. When examining incidence in small areas, the traditionally used estimate is the SIR (indirectly Standardised Incidence Ratio). The SIR is an estimate of relative risk within each area which compares the observed counts against an expected number of counts, based on the population size.

However, limitations associated with the SIR estimates have been previously noted [38]. For example, large differences can be observed in the SIR estimates even with relatively small changes in incidence counts, and areas with no cases automatically receive an SIR of zero, regardless of the expected counts [40].

Modelling the SIR via spatial or Bayesian methods overcomes many of these problems by producing more reliable and robust estimates. Although there are many advantages to using a modelled SIR, they reflect the comparison of SLA-specific estimates against the Queensland average and not comparisons between SLAspecific estimates themselves. The latter interpretation may be biased if the SLAs have different population age structures and the outcome measure varies by age. For this reason the maps must be interpreted in terms of which areas are higher or lower than the Queensland 
Table 2 Selected Cancer Atlases published from 1995 onwards

\begin{tabular}{|c|c|c|c|c|c|c|c|}
\hline Region & $\begin{array}{l}\text { Time } \\
\text { period }\end{array}$ & Outcome & $\begin{array}{l}\text { Statistic } \\
\text { mapped }\end{array}$ & Smoothing method & $\stackrel{\mathrm{N}}{\text { regions }^{\mathrm{a}}}$ & $\begin{array}{l}\mathrm{N} \text { cancers } \\
\text { mapped }^{\mathbf{b}}\end{array}$ & $\begin{array}{l}\text { Presentation } \\
\text { method }^{\mathrm{c}}\end{array}$ \\
\hline Canada [63] & 1986-1990 & Incidence & $\mathrm{CIF}$ & None & 290 & $17(\mathrm{M}, \mathrm{F}$ or $\mathrm{P})$ & Ecumene \\
\hline Europe [64] & 〜 1981-1990 & $\begin{array}{l}\text { Incidence } \\
\text { Mortality }\end{array}$ & DSR & $\begin{array}{l}\text { Floating average of neighbouring } \\
\text { rates for non-cities }\end{array}$ & $\begin{array}{c}\text { Not } \\
\text { stated }\end{array}$ & $31(\mathrm{M}, \mathrm{F})$ & Isopleth \\
\hline India [65] & $2001-2002$ & Incidence & DSR & None & 593 & $1(\mathrm{M}, \mathrm{F})$ & Areal \\
\hline $\begin{array}{l}\text { Limburg [66] } \\
\text { (Belgium) }\end{array}$ & 1996-1998 & Incidence & $\mathrm{SIR}$ & $\begin{array}{c}\text { Poisson-Gamma and CAR Bayesian } \\
\text { models }\end{array}$ & 44 & $5(M, F)$ & Areal \\
\hline Netherlands [67] & 1989-2003 & Incidence & DSR & $\begin{array}{l}\text { Floating average of neighbouring } \\
\text { rates for non-cities }\end{array}$ & 458 & $11(\mathrm{M}, \mathrm{F})$ & Isopleth \\
\hline New York [68] (USA) & Not stated & Incidence & DSR & None & 62 & $12(\mathrm{M}, \mathrm{F})$ & Areal \\
\hline $\begin{array}{l}\text { New South Wales } \\
\text { [46] (Australia) }\end{array}$ & 1998-2002 & $\begin{array}{l}\text { Incidence } \\
\text { Mortality }\end{array}$ & SIR, SMR & CAR Bayesian model & 192 & $\begin{array}{l}22-\operatorname{inc}(M, F) \\
12-\operatorname{mort}(M, F)\end{array}$ & Areal \\
\hline $\begin{array}{l}\text { Pennsylvania [69] } \\
\text { (USA) }\end{array}$ & 1994-2002 & Incidence & DSR & None & 67 & $2(M, F, P)$ & Areal \\
\hline $\begin{array}{l}\text { Queensland [20] } \\
\text { (Australia) }\end{array}$ & 1998-2007 & $\begin{array}{l}\text { Incidence } \\
\text { Survival }\end{array}$ & SIR, RER & $\begin{array}{c}\text { Bayesian hierarchical models: BYM } \\
\text { and relative survival }\end{array}$ & 478 & $19(\mathrm{M}, \mathrm{F})$ & Areal \\
\hline $\begin{array}{l}\text { South Australia [70] } \\
\text { (Australia) }\end{array}$ & $1991-2000$ & $\begin{array}{l}\text { Incidence } \\
\text { Mortality }\end{array}$ & DSR & None & 117 & $11(P)$ & Ecumene \\
\hline Spain [71] & 1987-1995 & Mortality & SIR & $\begin{array}{l}\text { Non-parametric empirical Bayes } \\
\text { estimation method }\end{array}$ & 2218 & $\begin{array}{c}4(\mathrm{M}, \mathrm{F}) \text { out of } \\
14 \text { maps }\end{array}$ & Areal \\
\hline Sweden [72] & 1971-1989 & Incidence & DSR, CIF & None & 286 & $37(\mathrm{M}, \mathrm{F})$ & Areal \\
\hline UK [73] & $2003-2005$ & $\begin{array}{c}\text { Incidence } \\
\text { Survival Mortality }\end{array}$ & DSR, RS & None & 350 & $17(M, F, P)$ & Areal \\
\hline UK/Ireland [74] & $1991-2000$ & $\begin{array}{l}\text { Incidence } \\
\text { Mortality }\end{array}$ & CIF or CMF & None & 127 & $21(\mathrm{M}, \mathrm{F})$ & Areal \\
\hline USA [75] & 1950-1994 & Mortality & DSR, CIF & None & 3055 & $41(\mathrm{M}, \mathrm{F})$ & Areal \\
\hline
\end{tabular}

a. When multiple areas are available, as for some of the online Atlases, the number of regions is the number at the most detailed level.

b. $\mathrm{M}=$ males, $\mathrm{F}=$ females and $\mathrm{P}=$ persons.

c. Ecumene means only populated areas were coloured, Areal indicates that each individual region was coloured, and Isopleth means a continuous gradient was used.

BYM = Besag, York and Mollié

$\mathrm{CAR}=$ Conditional AutoRegressive.

$\mathrm{CIF} / \mathrm{CMF}=$ Comparative Incidence/Mortality Figure, and is the ratio of the DSR of the area to the DSR of the entire region or country.

DSR $=$ Directly age Standardised Rates.

$\mathrm{RER}=$ Relative Excess Risk of death

RS = Relative Survival.

SIR/SMR = indirectly Standardised Incidence/Mortality Ratio.

average [48]. Alternative measures, such as the Comparative Incidence Figure (CIF, which is the ratio of the local to national (or whole region) directly standardized rates, i.e. rates weighted by age groups using an external population), have been proposed to overcome this issue, but these have their own disadvantages, including larger standard errors [49]. In light of these evaluations, the modelled SIR was adopted.

\section{Survival estimates}

Typically, cancer atlases have tended to report variations in cancer mortality, rather than cancer survival (Table 2). However spatial variations in cancer mortality reflect differences according to where people die, which may not be where they resided when diagnosed or treated. Mortality data are also prone to bias from death certificate inaccuracies in cause of death classification [50]. In contrast, mapping cancer survival, which is the percentage of patients who survive for a given time after diagnosis, estimates the variation in outcomes based on where people lived when diagnosed. Since treatment generally occurs shortly following diagnosis, this better reflects the potential impact of barriers to treatment and support services.

Survival after the diagnosis of cancer is the most important single measure for monitoring and evaluating the early diagnosis and treatment components of cancer control [51]. When examining cancer survival using population-based data, relative survival is often the preferred method as it provides an estimate of the net cancer survival without errors from cause of death misclassification, including difficulties in assigning cause of death when cancer was a contributing cause, but may not be completely responsible for the death $[52,53]$.

Relative survival aims to measure deaths in excess of what would be expected, that is, the proportion of 
cancer patients alive $\mathrm{x}$ years after diagnosis in the hypothetical situation where the cancer in question is the only possible cause of death. Relative survival is modelled via an excess mortality model, which contrasts the mortality in the general population with the mortality of cancer patients. The difference is assumed to be due to cancer-related deaths ('excess mortality'). This model generates the excess hazard, also called relative excess risk (RER).

The median smoothed RER (i.e. exponential of the sum of the spatial and random heterogeneity components) was mapped. Similar to the interpretation of the SIR, the RER is a comparison against the State average, and comparison between areas is not recommended.

\section{Bayesian hierarchical models Incidence}

For incidence models the Besag, York and Mollié (BYM) model was used, as it has been shown to have desirable properties for disease mapping [43]. This model is specified as: $\begin{aligned} & y_{i} \sim \operatorname{Poisson}\left(e_{i} \theta_{i}\right) \\ & \log \left(\theta_{i}\right)=\alpha+u_{i}+v_{i}\end{aligned}$

where $e_{i}$ is the expected number of cases for the $i$ th SLA, $\theta_{i}$ is the standardised incidence ratio, $\alpha$ is the overall level of relative risk, $u_{i}$ is the spatial component modelled with the conditional autoregressive (CAR) prior, and $v_{i}$ is the unstructured random effects (which has a normal distribution centered around zero). Input data were aggregated over 1998 to 2007. Since incidence is likely to differ by gender, estimates for males and females were generated separately.

Since this is a fully Bayesian model, priors were specified for $\alpha, u_{i}$ and $v_{i}$. The prior for $\alpha$ was given a vague normal distribution with mean 0 and variance of $1.0 \times$ $10^{10}$. The prior distributions for $u_{i}$ and $v_{i}$ required sensitivity analyses, and are discussed below.

\section{Relative survival}

For relative survival, a recommended approach is to model excess mortality under a generalized linear model based on collapsed data using exact survival times and a Poisson assumption [52]. The basic version of this model was extended to include spatial and random effects, similar to Fairley et al [54].

$$
\begin{gathered}
d_{k j i} \sim \operatorname{Poisson}\left(\mu_{k j i}\right) \\
\log \left(\mu_{k j i}-d_{k j i}^{*}\right)=\log \left(\gamma_{k j i}\right)+\alpha_{j}+\mathrm{x} \beta_{k}+u_{i}+v_{i}
\end{gathered}
$$

Where $y_{k j i}$ is person-time at risk in the $k$ th age group, the $j$ th follow up interval and the $i$ th SLA, $d_{k j i}^{*}$ is the expected number of deaths due to causes other than the cancer of interest, $\alpha_{j}$ is the intercept (which varied by follow-up year), $\beta_{k}$ is the coefficient of the predictor variable vector $\times$ (representing the broad age groups), $v_{i}$ is the unstructured random effects (which has a normal distribution) and $u_{i}$ is the spatial component modelled with the CAR prior. Both $\alpha$ and $\beta$ were given priors with normal distributions having mean 0 and variance $1.0 \times 10^{6}$. The model was run separately for males and females. Broad age groups were included in the model to prevent bias due to differing age structures between SLAs.

All cases considered 'at risk' during 1998 to 2007 were included. Since the earliest year of data was 1996, this meant that any cases diagnosed from 1996 onwards which were alive with up to 5 years follow-up at some stage during 1998-2007 were included. Cases alive on the $31^{\text {st }}$ December 2007 were considered censored.

This model excluded persons aged 90 years or older at time of diagnosis, those whose diagnosis was based on death certificate or autopsy only, or those with a survival time of zero days or less. In total, this was $3.3 \%$ of the records from 1996-2007.

\section{Adjacency matrix}

Since the Bayesian models incorporate information from neighbouring regions, it is necessary to specify the definition of which SLAs are considered neighbours. An adjacency matrix is generated to apply these definitions in the Bayesian model. Using the standard terminology for adjacency options, which follow the possible moves of chess pieces, we used the "Queen" definition, so that SLAs were considered to be neighbours if they shared a common border [55]. The adjacency matrix was calculated using the program GeoDa [56] using $1^{\text {st }}$ order queen adjacencies. Although it is possible to use higherorder weights than first-order (e.g. second-order weights will include neighbours of neighbours), this was not considered useful for this analysis due to the much denser neighbourhood matrix and, particularly in rural areas of the state, the very large distances between second-order neighbouring SLAs.

Due to the large number of island SLAs in Queensland, 18 regions originally had no neighbours. Since estimates will not be smoothed unless a region has neighbours the default neighbourhood matrix was adjusted to ensure all regions had at least one neighbour. Additional neighbours were incorporated by considering they could share a border even if separated by a river, or a sea. In particular, most of the Far North islands were grouped together, with some mainland areas also included to ensure enough strength was provided to generate meaningful estimates that were able to converge.

\section{Computation}

Models were run using WinBUGS [57] interfaced with Stata [58] (using the wb commands written by John 
Thompson, University of Leicester [59]) with a burn-in period of 100,000 iterations (incidence models) and 250,000 iterations (survival models) followed by 100,000 iterations. To decrease the correlation between iterations a subsample of every tenth iteration was kept. Only one chain was run for each estimate.

\section{Assessing convergence}

Convergence was assessed using visual examination of trace, density and autocorrelation plots, as well as the Geweke diagnostic [60]. Geweke diagnostics were calculated as the difference between the means for the first 1000 iterations (10\%) that were kept and the final 5000 iterations (50\%), divided by the asymptotic standard error of the difference. These were generated for the SIR or RER estimates for all 478 SLAs, and any estimate that had a Geweke estimate with a p-value of less than 0.01 was considered unlikely to have converged. To save disk space and processing time, trace and density plots were only generated for $5 \%$ (n $=24$ ) of the SLAs, composed of SLAs of concern due to small numbers as well as a random selection.

\section{Sensitivity analyses}

For these types of models, and particularly when data are sparse, it is vital to carefully consider the choice of prior and compare the effects of alternate priors. The priors used on the distribution for the variance of the spatial and random effects components may particularly influence the results.

There were three stages to conducting the sensitivity analyses. First, the literature was searched to determine what priors were being used in similar models. Many BYM models were found, however, there were few examples of Bayesian relative survival models containing spatial components. As there was no other source of information relevant to the study at hand on which to base informative priors, a range of non-informative priors were used for the relative survival models. Second, the performance of each prior was evaluated. Since the potential influence of the prior will be more pronounced for scarce data, Tables 3 and 4 show some of the comparative numbers for a less common cancer oesophageal cancer in males. In addition to these, observed values were plotted against those predicted by the model and quantile-quantile plots were examined. Third, convergence was examined, as outlined earlier. Lack of convergence could indicate a poor model, or it may simply indicate a longer burn-in period is required. Monitoring the estimate over the entire number of iterations (including burn-in) would show whether it is likely convergence will eventually be reached. In tables 3 and 4 the proportion of SLAs for which the SIR or RER estimate did not converge after discarding 50,000 iterations is shown.

Table 3 Sensitivity analyses for oesophageal cancer incidence among males

\begin{tabular}{|c|c|c|c|c|c|c|}
\hline & Prior 1 & Prior 2 & Prior 3 & Prior 4 & Prior 5 & Prior 6 \\
\hline \multicolumn{7}{|l|}{ Distribution of SIR } \\
\hline Mean & 100.8 & 99.4 & 101.5 & 100.7 & 100.6 & 103.6 \\
\hline Standard deviation & 10.2 & 30.8 & 16.3 & 14.5 & 13.5 & 23.2 \\
\hline Maximum & 140.6 & 455.1 & 181.2 & 169.5 & 166.4 & 201.8 \\
\hline 75\% Quartile & 107.2 & 113.1 & 111.7 & 110.2 & 109.4 & 109.8 \\
\hline Median & 96.5 & 93.5 & 95.1 & 95.6 & 95.9 & 95.7 \\
\hline 25\% Quartile & 93.3 & 78.7 & 89.4 & 89.9 & 90.7 & 90.2 \\
\hline Minimum & 87.4 & 55.9 & 79.6 & 79.3 & 80.0 & 79.8 \\
\hline $90 \%$ ratio $^{1}$ & 1.3 & 2.3 & 1.6 & 1.5 & 1.5 & 1.6 \\
\hline$\overline{p D^{2}}$ & 34.112 & 138.047 & 51.305 & 53.828 & 53.709 & 54.098 \\
\hline $\mathrm{DIC}^{3}$ & 1652.57 & 1660.32 & 1650.62 & 1648.51 & 1651.02 & 1650.71 \\
\hline Spatial fraction ${ }^{4}$ & 0.56 & 0.44 & 0.63 & 0.48 & 0.52 & 0.57 \\
\hline Percent SLAs with Geweke $<0.01$ for SIR & $41.0 \%$ & $1.9 \%$ & $3.3 \%$ & $9.4 \%$ & $10.3 \%$ & $10.5 \%$ \\
\hline
\end{tabular}

Notes:

1. The $90 \%$ ratio is calculated as the $95^{\text {th }}$ percentile divided by the $5^{\text {th }}$ percentile of the smoothed SIR estimates.

2. $\mathrm{pD}$ represents the effective number of parameters in the model. Larger values indicate less smoothing of estimates.

3. $\mathrm{DIC}=$ Deviance Information Criterion. Smaller values (of at least 5 below) indicate a better model fit.

4. The spatial fraction estimates the relative contribution of spatial and unstructured heterogeneity, and is calculated as:

Spatial fraction $=\frac{\theta_{\text {marginal }}^{2}}{\theta_{\text {marginal }}^{2}+\sigma^{2}}$

where $\theta_{\text {marginal }}^{2}=$ marginal spatial variance, $\sigma^{2}=$ marginal variability of the unstructured random effects between areas. A value close to 1 indicates the spatial heterogeneity dominates, whereas a value close to 0 indicates the unstructured heterogeneity dominates. 
Table 4 Sensitivity analyses for oesophageal cancer survival among males

\begin{tabular}{|c|c|c|c|c|c|c|}
\hline & Prior 1 & Prior 2 & Prior 3 & Prior 4 & Prior 5 & Prior 6 \\
\hline \multicolumn{7}{|l|}{ Distribution of RER } \\
\hline Mean & 100.2 & 100.7 & 100.4 & 100.1 & 100.4 & 100.0 \\
\hline Standard deviation & 6.5 & 11.5 & 8.2 & 3.8 & 9.3 & 0.3 \\
\hline Maximum & 119.6 & 140.7 & 127.6 & 111.3 & 129.5 & 102.1 \\
\hline 75\% Quartile & 105.3 & 105.0 & 105.7 & 102.6 & 106.3 & 100.2 \\
\hline Median & 98.0 & 97.3 & 97.7 & 99.2 & 97.0 & 100.0 \\
\hline 25\% Quartile & 95.2 & 92.6 & 94.7 & 97.2 & 93.7 & 99.8 \\
\hline Minimum & 80.9 & 63.4 & 75.0 & 89.4 & 72.5 & 98.3 \\
\hline $90 \%$ ratio $^{1}$ & 1.2 & 1.4 & 1.3 & 1.1 & 1.3 & 1.0 \\
\hline $\mathrm{pD}^{2}$ & 23.988 & 36.021 & 33.105 & 18.663 & 30.524 & 18.218 \\
\hline $\mathrm{DIC}^{3}$ & 3690.23 & 3690.27 & 3691.24 & 3691.32 & 3690.07 & 3694.96 \\
\hline Spatial fraction ${ }^{4}$ & 0.62 & 0.87 & 0.51 & 0.48 & 0.80 & 0.00 \\
\hline Percent SLAs with Geweke $<0.01$ for RER & $89.3 \%$ & $9.8 \%$ & $10.5 \%$ & $19.5 \%$ & $21.5 \%$ & $63.0 \%$ \\
\hline
\end{tabular}

Notes:

1. The $90 \%$ ratio is calculated as the $95^{\text {th }}$ percentile divided by the $5^{\text {th }}$ percentile of the smoothed RER estimates.

2. $\mathrm{pD}$ represents the effective number of parameters in the model. Larger values indicate less smoothing of estimates.

3. $\mathrm{DIC}=$ Deviance Information Criterion. Smaller values (of at least 5 below) indicate a better model fit.

4. The spatial fraction estimates the relative contribution of spatial and unstructured heterogeneity, and is calculated as:

Spatial fraction $=\frac{\theta_{\text {marginal }}^{2}}{\theta_{\text {marginal }}^{2}+\sigma^{2}}$

Where $\theta_{\text {marginal }}^{2}=$ marginal spatial variance, $\sigma^{2}=$ marginal variability of the unstructured random effects between areas. A value close to 1 indicates the spatial heterogeneity dominates, whereas a value close to 0 indicates the unstructured heterogeneity dominates.

For the sensitivity tests some of the less common cancers were examined (for incidence: oesophageal, brain, myeloma; for survival (based on number of deaths): oesophageal, thyroid), as well as a more common one (incidence: melanoma; survival: pancreatic).

For both the incidence and survival models, $u$ represents the spatial component, while $v$ represents the random component. These components were each given hyperprior distributions, as below:

$$
\begin{gathered}
v_{i} \sim N\left(0, \tau_{v}^{2}\right) \\
{\left[u_{i} \mid u_{j}, i \neq j, \tau_{u}^{2}\right] \sim N\left(\bar{\mu}_{i}, \tau_{i}^{2}\right)} \\
\text { where } \bar{\mu}_{i}=\frac{1}{\Sigma_{j} \omega_{i j}} \Sigma_{j} \mu_{j} \omega_{i j} \\
\tau_{i}^{2}=\frac{\tau_{u}^{2}}{\Sigma_{j} \omega_{i j}}
\end{gathered}
$$

$\omega_{i j}=1$ if SLAs $i, j$ are adjacent (or 0 if they are not).

The $\tau$ values control the variability of $u$ and $v$. As such, the distribution can be specified using $\tau$ or $\sigma$, which is the square root of the inverse of $\tau$ (variance $=\sigma^{2}$ ).

The following priors were compared for the incidence model:

1. $\tau_{u} \sim \operatorname{Gamma}(0.5,0.0005), \tau_{v} \sim \operatorname{Gamma}(0.5$, 0.0005)
2. $\tau_{u} \sim \operatorname{Gamma}(1,1), \tau_{v} \sim \operatorname{Gamma}(7.801,2.793)$

3. $\tau_{u} \sim \operatorname{Gamma}(0.1,0.1), \tau_{v} \sim \operatorname{Gamma}(0.001,0.001)$

4. $\tau_{u} \sim \operatorname{Gamma}(0.1,0.01), \tau_{v} \sim \operatorname{Gamma}(0.1,0.01)$

5. Reparameterised on $\sigma: \sigma_{u} \sim \operatorname{Uniform}(0,1), \sigma_{v} \sim$ Uniform $(0,1)$

6. Reparameterised on $\sigma: \sigma_{u} \sim$ Uniform $(0,1000), \sigma_{v}$ $\sim$ Uniform $(0,1000)$

Prior 1 shrunk the estimates more than any other (the $\mathrm{pD}$ value is lower than the others, and the standard deviation smaller) (Table 3). Prior 2 induced far less shrinkage than the others (higher $\mathrm{pD}$ and standard deviation). Prior 2 also had a larger DIC (greater than 6 above the others), indicating worse model fit. Priors 3 to 6 gave fairly similar results, although prior 6 had a larger standard deviation.

It was decided to use prior 3 as it provided consistently plausible results and converged well across the range of cancers examined.

For the survival model, the following non-informative priors were compared:

1. $\tau_{u} \sim \operatorname{Gamma}(0.5,0.001), \tau_{v} \sim \operatorname{Gamma}(0.5,0.001)$

2. $\tau_{u} \sim \operatorname{Gamma}(0.1,0.1), \tau_{v} \sim \operatorname{Gamma}(0.001,0.001)$

3. $\tau_{u} \sim \operatorname{Gamma}(0.1,0.01), \tau_{v} \sim \operatorname{Gamma}(0.1,0.01)$

4. $\tau_{u} \sim \operatorname{Gamma}(0.5,0.0005), \tau_{v} \sim \operatorname{Gamma}(0.5$, $0.0005)$

5. Reparameterised on $\sigma: \sigma_{u} \sim$ Uniform $(0,1), \sigma_{v} \sim$ Uniform $(0,1)$

6. Reparameterised on $\sigma: \sigma_{u} \sim$ Uniform $(0,1000), \sigma_{v}$

$\sim$ Uniform $(0,1000)$ 
Prior 3 was chosen because it demonstrated greater convergence properties across the range of cancers examined, while restricting the results to a narrower range of smoothed estimates than Prior 2 (Table 4).

\section{Production of maps}

A thematic scheme was chosen, with colours determined using color brewer http://colorbrewer2.org under the specifications of a diverging colour-scheme of 5 categories which are suitable for print and colour-blind friendly (Figure 1). The SIRs and RERs were categorised as $10 \%$ above and $30 \%$ above the State average, and the inverse of these for the lower cut-offs. There is great variability in the categories used in other atlases, but these fairly broad categories were used to reduce the probability of reporting spuriously significant differences.

Mapping alternative measures, such as the posterior probability of exceeding a certain value, were considered, but were deemed unsatisfactory due to difficulties in interpretation and the lack of information provided in regards to the size of the risk $[27,44]$. Therefore we used graphs to show the precision of the mapped estimates.

\section{Graphs}

To supplement the information provided in the maps, a graph showing the ranked SIR or RER with the associated 95\% credible interval for each SLA was provided (Figure 2). Horizontal box plots of the SIR or RER estimates by socioeconomic status and rurality were also provided to provide additional information about where the extent of variability across the state (Figure 2). Since a primary purpose of the model was to provide overall estimates of variability across the State, we did not include these additional variables in the model.

\section{Additional data included}

For each cancer with significant variation, SIR or RER estimates with $95 \%$ credible intervals were also provided by socioeconomic and rurality classifications. To calculate these, each iteration of the 10,000 iterations had the modelled observed value (incidence) and the adjusted deaths value (survival) calculated as above. For survival (which incorporated age group and time period) these were summed to give 10,000 iterations for each SLA. Each SLA was then grouped into rurality or socioeconomic status

\section{Risk of diagnosis}

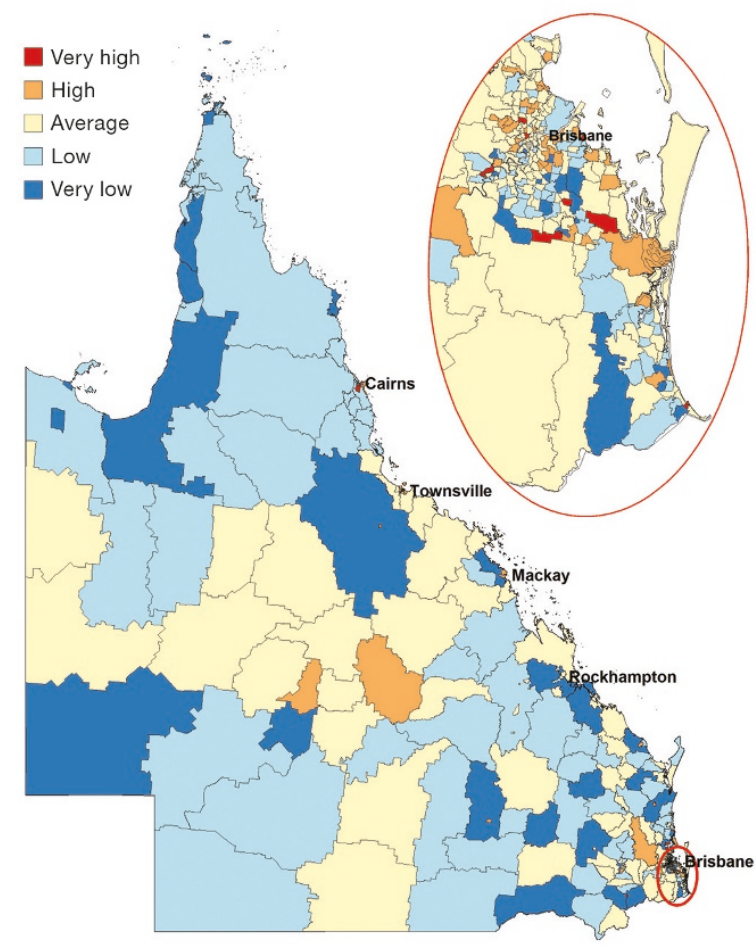

\section{Risk of death within 5 years of diagnosis}

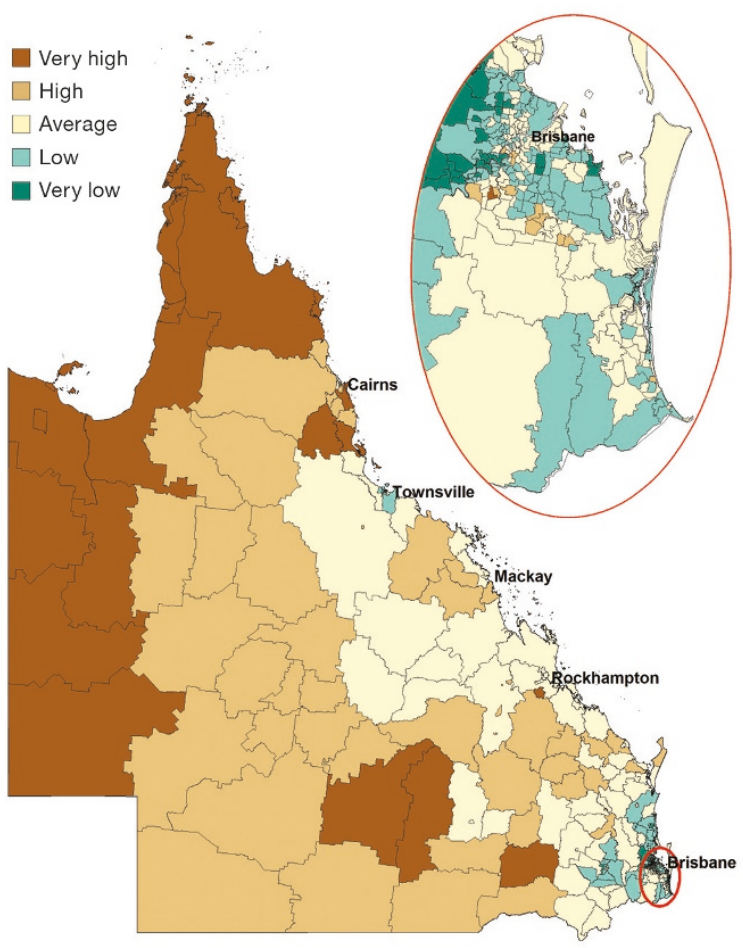

Figure 1 An example of the incidence (risk of diagnosis) and survival (risk of death within 5 years of diagnosis) maps for all invasive cancers, males. 


\section{Level of Uncertainty}

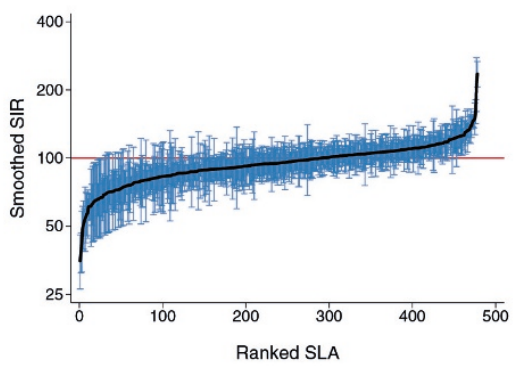

\section{Distribution of smoothed SIR estimates by:}

a) Socioeconomic status

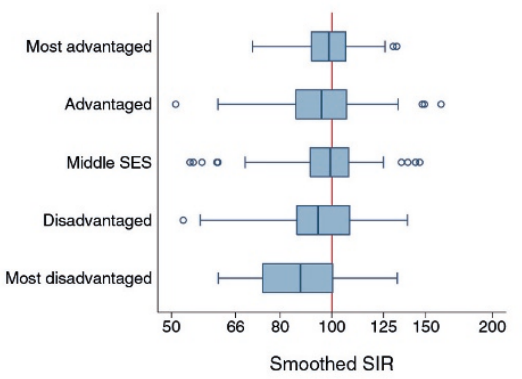

b) Rurality

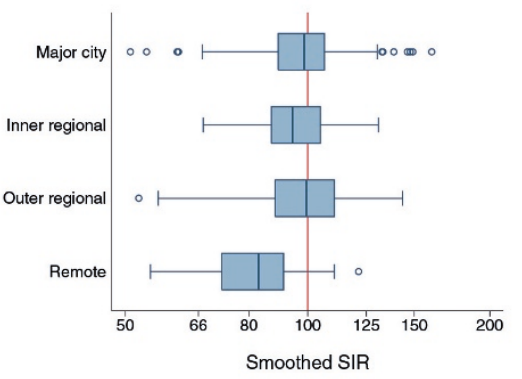

Figure 2 An example of the incidence graphs for all invasive cancers, males.

categories, and the adjusted estimates summed. These were divided by the original expected values to produce 10,000 SIR or RER estimates by rurality and socioeconomic status categories. The median of these 10,000 was used as the SIR or RER point estimate, and the 2.5 and 97.5 percentiles used to provide the lower and upper credible interval estimates, respectively.

\section{Determining whether observed variation is significant}

Once the results have been produced and mapped, it is important to determine whether the apparent variation reflects true geographic differences. Therefore, a test for global clustering was conducted. Multiple tests are available [19], such as Besag-Newell's R, Moran's I, Oden's Ipop, but we elected to use Tango's MEET (Maximised Excess Events Test) [61] as it has been shown to perform well across a variety of datasets [19].

A small p-value from Tango's MEET indicates that estimates differ between regions. As is consistent with standard statistical analysis [62], adjusted p-values from the Tango's MEET statistic below 0.01 were considered to strongly indicate spatial variation, while values between 0.05 and 0.01 were moderately indicative of variation. Values of 0.05 or above were considered to not be significant, however two categories were defined. Values between 0.05 and 0.10 were considered to provide only weak evidence of geographic variation, while values above 0.10 no evidence of geographical variation.

Since Tango's MEET is calculated using Monte Carlo replications, it is expected that there could be slight variations in the results. To increase our confidence that the final classification of geographic variation was stable, Tango's MEET was run an additional 5 times for each cancer and gender combination. There were only two cases where the final classification did change for different replication, and so these cancers were assigned to the more conservative, less significant category.

Input for Tango's MEET requires an observed and expected value. Since the modelled results were of interest, the modelled observed value needed to be calculated. For the incidence data, the observed value was calculated by the smoothed SIR median value multiplied by the expected value to produce a modelled observed value. For the relative survival model, the adjusted deaths for each data point were calculated as: (person-time at risk $x$ $\exp ^{\text {follow-up time }} \times \exp ^{\text {age group }} \times$ RER) + expected number of deaths due to causes other than the cancer of interest.

i.e. $\left(y_{k j i} \times e^{\alpha_{j}} \times e^{\beta_{k}} \times e^{u_{i}+v_{i}}\right)+d_{k j i}^{*}$

These were then added together for each SLA to provide the input data for Tango's MEET.

\section{Conclusions}

Chronic disease atlases are a useful tool for assessing and quantifying geographical inequalities, as well as assisting to focus research efforts in investigating why the observed inequalities exist. When developing these atlases, a myriad of decisions concerning how to model and present the results need to be made and this paper presents one decision-making algorithm used to generate a cancer atlas.

There are several priority areas for future consideration in disease mapping including communicating spatial results, particularly finding ways to present the uncertainty surrounding the results; and the development and use of alternative statistical models such as classification and regression tree (CART) models. In addition, more detailed statistical models can be developed to investigate the impact of rurality, area-level and individual level socioeconomic status as well as temporal changes. 
As with all chronic disease atlases, it is hoped that the presented variations in outcomes will stimulate further research efforts to investigate the reasons underlying the disparities and inform advocacy, policy, support and education programs to effectively address these, so that health equity will become a reality.

The full report is available (from February 2011) at: http://www.cancerqld.org.au/pdf/cancer_atlas.pdf

\section{Author details}

${ }^{1}$ Viertel Centre for Research in Cancer Control, Cancer Council Queensland, Gregory Tce, Fortitude Valley, Australia. ${ }^{2}$ Centre for Data Analysis, Modelling and Computation, Queensland University of Technology, George St, Brisbane, Australia. ${ }^{3}$ School of Public Health, Queensland University of Technology, Herston Rd, Kelvin Grove, Australia.

\section{Authors' contributions}

PDB and KLM conceived the study. SMC performed the analysis. SMC and PDB drafted the manuscript. All authors contributed to, read and approved the final manuscript.

\section{Competing interests}

The authors declare that they have no competing interests.

Received: 30 September 2010 Accepted: 24 January 2011

Published: 24 January 2011

\section{References}

1. World Health Organization: Declaration of Alma-Ata. International Conference on Primary Health Care, Alma-Ata, USSR, 6-12 September 19781978.

2. Gondos A, Holleczek B, Arndt V, Stegmaier C, Ziegler H, Brenner H: Trends in population-based cancer survival in Germany: to what extent does progress reach older patients? Ann Oncol 2007, 18:1253-1259.

3. Coleman MP, Gatta G, Verdecchia A, Esteve J, Sant M, Storm H, Allemani C, Ciccolallo L, Santaquilani M, Berrino F: EUROCARE-3 summary: cancer survival in Europe at the end of the 20th century. Ann Oncol 2003, 14(Suppl 5):v128-149.

4. National Cancer Institute: Cancer Trends Progress Report - 2009/2010 Update Bethesda: NCl, NIH, DHHS; 2010.

5. Woods LM, Rachet B, Coleman MP: Origins of socio-economic inequalities in cancer survival: a review. Ann Oncol 2006, 17:5-19.

6. Wilkinson D, Cameron K: Cancer and cancer risk in South Australia: what evidence for a rural-urban health differential? Aust J Rural Health 2004 12:61-66.

7. Ernst J, Zenger M, Schmidt R, Schwarz R, Brahler E: [Medical and psychosocial care needs of cancer patients: a systematic review comparing urban and rural provisions]. Dtsch Med Wochenschr 2010, 135:1531-1537.

8. Armstrong BK, Gillespie JA, Leeder SR, Rubin GL, Russell LM: Challenges in health and health care for Australia. Med J Aust 2007, 187:485-489.

9. Australian Institute of Health and Welfare, Cancer Australia \& Australasian Association of Cancer Registries: Cancer survival and prevalence in Australia: cancers diagnosed from 1982 to 2004 Canberra: AlHW; 2008.

10. Jong KE, Smith DP, Yu XQ, O'Connell DL, Goldstein D, Armstrong BK: Remoteness of residence and survival from cancer in New South Wales. Med J Aust 2004, 180:618-622.

11. Australian Institute of Health and Welfare: A snapshot of men's health in regional and remote Australia Canberra: AlHW; 2010.

12. Australian Institute of Health and Welfare: Rural, regional and remote health: indicators of health status and determinants of health Canberra: AlHW; 2008

13. Armstrong K, O'Connell DL, Leong D, D SA, Armstrong BK: The New South Wales Colorectal Cancer Care Survey Part 1-Surgical Management Sydney: The Cancer Council NSW; 2004

14. Coory MD, Baade PD: Urban-rural differences in prostate cancer mortality, radical prostatectomy and prostate-specific antigen testing in Australia. Med J Aust 2005, 182:112-115.
15. Kricker A, Haskill J, Armstrong BK: Breast conservation, mastectomy and axillary surgery in New South Wales women in 1992 and 1995. Br J Cancer 2001, 85:668-673.

16. Pickle LW: A history and critique of U.S. mortality atlases. Spatial and Spatio-temporal Epidemiology 2009, 1:3-17.

17. Lawson AB: Bayesian Disease Mapping: Hierarchical Modeling in Spatial Epidemiology Boca Raton: CRC Press; 2008.

18. Mason TJ, McKay FW, Hoover R, Blot WJ, Fraumeni JF: Atlas of cancer mortality for U.S. counties: 1950-1969 Washington: U.S. Govt. Printing Office; 1975.

19. Kulldorff M, Song C, Gregorio D, Samociuk H, DeChello L: Cancer map patterns: are they random or not? Am J Prev Med 2006, 30:S37-49.

20. Cramb SM, Mengersen KL, Baade PD: Atlas of Cancer in Queensland: geographical variation in incidence and survival, 1998 to 2007 Brisbane: Viertel Centre for Research in Cancer Control, Cancer Council Queensland; 2011.

21. Australian Bureau of Statistics: 3235.0 - Population by Age and Sex, Regions of Australia, 20072008

22. Australian Bureau of Statistics: Australian Social Trends 2003 Canberra: ABS; 2003.

23. Australian Institute of Health and Welfare, Australasian Association of Cancer Registries: Cancer in Australia: an overview, 2008 Canberra: AlHW 2008.

24. Bhowmick T, Robinson AC, Gruver A, MacEachren AM, Lengerich EJ: Distributed usability evaluation of the Pennsylvania Cancer Atlas. Int J Health Geogr 2008, 7:36.

25. Boulos M: Towards evidence-based, GIS-driven national spatial health information infrastructure and surveillance services in the United Kingdom. International Journal of Health Geographics 2004, 3:1.

26. Jacquez GM: Current practices in the spatial analysis of cancer: flies in the ointment. Int J Health Geogr 2004, 3:22

27. Bell BS, Hoskins R, Pickle L, Wartenberg D: Current practices in spatial analysis of cancer data: mapping health statistics to inform policymakers and the public. International Journal of Health Geographics 2006, 5:49.

28. Henry KA, Niu X, Boscoe FP: Geographic disparities in colorectal cancer survival. Int J Health Geogr 2009, 8:48.

29. DeChello LM, Sheehan TJ: Spatial analysis of colorectal cancer incidence and proportion of late-stage in Massachusetts residents: 1995-1998. Int J Health Geogr 2007, 6:20.

30. Bilancia M, Fedespina $A$ : Geographical clustering of lung cancer in the province of Lecce, Italy: 1992-2001. Int J Health Geogr 2009, 8:40.

31. Queensland Cancer Registry: Cancer in Queensland: Incidence, Mortality, Survival and Prevalence,1982 to 2007 Brisbane: QCR, Cancer Council Queensland and Queensland Health; 2010

32. Australian Bureau of Statistics: Unit record mortality data for Queensland by State of usual residence, 1982-2007 Canberra: ABS; 2009.

33. Australian Bureau of Statistics: Australian Standard Geographic Classification (ASGC), 2006 Canberra: ABS; 2006.

34. Australian Bureau of Statistics: National Localities Index, Australia Canberra: ABS; 2007.

35. Australian Bureau of Statistics: Census of Population and Housing: SocioEconomic Indexes for Areas (SEIFA), Australia, 2006 Canberra: ABS; 2008.

36. Glover J, Tennant S: Remote areas statistical geography in Australia: Notes on the Accessibility/Remoteness Index for Australia (ARIA+version) Adelaide: Public Health Information Development Unit, The University of Adelaide; 2003.

37. Waller LA, Gotway CA: Applied spatial statistics for public health data New Jersey: Wiley; 2004

38. Lawson AB, Browne WJ, Vidal Rodeiro CL: Disease mapping with WinBUGS and MLwiN Chichester: John Wiley \& Sons Ltd; 2003

39. Goovaerts P: Geostatistical analysis of disease data: accounting for spatial support and population density in the isopleth mapping of cancer mortality risk using area-to-point Poisson kriging. Int J Health Geogr 2006, 5:52.

40. Lawson $A B$, Biggeri $A B$, Boehning $D$, Lesaffre $E$, Viel JF, Clark $A$, Schlattmann P, Divino F: Disease mapping models: an empirical evaluation. Disease Mapping Collaborative Group. Stat Med 2000 19:2217-2241.

41. Ghosh M, Natarajan K, Waller LA, Kim D: Hierarchical Bayes GLMs for the analysis of spatial data: An application to disease mapping. Journal of Statistical Planning and Inference 1999, 75:305-318. 
42. Bernardinelli L, Montomoli C: Empirical Bayes versus fully Bayesian analysis of geographical variation in disease risk. Stat Med 1992, 11:983-1007.

43. Best N, Richardson S, Thomson A: A comparison of Bayesian spatial models for disease mapping. Stat Methods Med Res 2005, 14:35-59.

44. Wakefield J: Disease mapping and spatial regression with count data. Biostatistics 2007, 8:158-183.

45. Shen W, Louis TA: Triple-goal estimates for disease mapping. Stat Med 2000, 19:2295-2308.

46. Bois JP, Clements MS, Yu XQ, Supramaniam R, Smith DP, Bovaird S, O'Connell DL: Cancer maps for New South Wales 1998 to 2002 Sydney: The Cancer Council NSW; 2007.

47. Buntinx F, Geys H, Lousbergh D, Broeders G, Cloes E, Dhollander D, Op De Beeck L, Vanden Brande J, Van Waes A, Molenberghs G: Geographical differences in cancer incidence in the Belgian province of Limburg. Eur $\lrcorner$ Cancer 2003, 39: 2058-2072.

48. Semenciw RM, Le ND, Marrett LD, Robson DL, Turner D, Walter SD: Methodological issues in the development of the Canadian Cancer Incidence Atlas. Stat Med 2000, 19:2437-2449.

49. Breslow N, Day N: The Design and Analysis of Cohort Studies Lyon: International Agency for Research on Cancer; 1987.

50. German RR, Fink AK, Heron M, Stewart SL, Johnson CJ, Finch JL, Yin D: The accuracy of cancer mortality statistics based on death certificates in the United States. Cancer Epidemiol .

51. Dickman PW, Lambert PC, Hakulinen T: Population-based Cancer Survival Analysis Chichester: Wiley;

52. Dickman PW, Sloggett A, Hills M, Hakulinen T: Regression models for relative survival. Stat Med 2004, 23:51-64.

53. Sarfati $D$, Blakely $T$, Pearce $N$ : Measuring cancer survival in populations: relative survival vs cancer-specific survival. Int J Epidemiol 2010, 39:598-610.

54. Fairley $L$, Forman $D$, West $R$, Manda $S$ : Spatial variation in prostate cancer survival in the Northern and Yorkshire region of England using Bayesian relative survival smoothing. Br J Cancer 2008, 99:1786-1793.

55. Earnest A, Morgan G, Mengersen K, Ryan L, Summerhayes R, Beard J: Evaluating the effect of neighbourhood weight matrices on smoothing properties of Conditional Autoregressive (CAR) models. Int I Health Geogr 2007, 6:54

56. Anselin L, Syabri I, Kho Y: GeoDa: An Introduction to Spatial Data Analysis. Geographical Analysis 2006, 38:5-22.

57. Lunn DJ, Thomas A, Best N, Spiegelhalter DJ: WinBUGS - a Bayesian modelling framework: concepts, structure, and extensibility. Statistics and Computing 2000, 10:325-337.

58. StataCorp: Stata Statistical Software: Release 11 College Station, TX: StataCorp LP; 2009

59. Thompson J, Palmer T, Moreno S: Bayesian analysis in Stata using WinBUGS. The Stata Journal 2006, 6:530-549.

60. Geweke J: Evaluating the accuracy of sampling-based approaches to the calculation of posterior moments. In Bayesian Statistics 4. Edited by: Bernardo JM, Berger J, Dawid AP, Smith AFM. Oxford: Oxford University Press; 1992:169-193.

61. Tango T: A test for spatial disease clustering adjusted for multiple testing. Stat Med 2000, 19:191-204.

62. McPherson G: Applying and Interpreting Statistics: A Comprehensive Guide. 2 edition. New York: Springer-Verlag New York Inc; 2001.

63. Le N, Marrett LD, Robson DL, Semenciw RM, Turner D, Walter SD: Canadian Cancer Incidence Atlas Ottawa: Ministry of Supply and Services; 1995.

64. Pukkala E, Söderman B, Okeanov A, Storm H, Rahu M, Hakulinen T, Becker N, Stabenow R, Bjarnadottir K, Stengrevics A, Gurevicius R, Glattre E, Zatonski W, Men T, Barlow L: Cancer atlas of Northern Europe Helsinki: Cancer Society of Finland; 2001.

65. Nandakumar A, Gupta PC, Gangadharan P, Visweswara RN: Development of an Atlas of Cancer in India: First all India report 2001-2002 Bangalore: National Cancer Registry Programme (ICMR); 2004.

66. Buntinx F, Cloes E, Dhollander D, Lousbergh D, Op De Beeck L, Rummens JL, Salk E, Vanden Brande J, Van Waes A: Incidence of Cancer in the Belgian Province of Limburg 1996-1998 Hasselt, Diepenbeek, Leuven: Limburgse Kankerstichting; 2000.

67. Netherlands Cancer Registry cancer incidence maps. [http://www.ikcnet. nl/page.php?id=2487\&nav_id=97].
68. New York State Department of Health Maps of Cancer Incidence by County. [http://www.health.state.ny.us/statistics/cancer/registry/cntymaps/ index.htm].

69. Pennsylvania Cancer Atlas: a CDC/GeoVISTA prototype. [http://www.geovista.psu.edu/grants/CDC].

70. SA Department of Health: The Geography of Cancer in South Australia, 19912000 Adelaide: SA Department of Health; 2005

71. Benach J, Yasui Y, Borrell C, Rosa E, Pasarín Ml, Benach N, Español E, Martínez JM, Daponte A: Atlas of mortality in small areas in Spain (19871995) Barcelona: UPF/MSD; 2001.

72. Swedish Oncological Centres: Atlas of Cancer Incidence in Sweden Stockholm: Swedish Oncological Centres; 1995

73. UK Association of Cancer Registries, Association of Public Health Observatories, Cancer Research UK and National Cancer Intelligence Network Cancer e-Atlas. [http://www.ncin.org.uk/cancer_information_tools/ eatlas.aspx].

74. Quinn M, Wood H, Cooper N, Rowan S, Eds: Cancer Atlas of the United Kingdom and Ireland 1991-2000. London: Office for National Statistics; 2005.

75. Devesa SS, Grauman DJ, Blot WJ, Pennello G, Hoover RN, Fraumeni JFJ: Atlas of cancer mortality in the United States, 1950-94 Washington: US Govt Print Off; 1999.

doi:10.1186/1476-072X-10-9

Cite this article as: Cramb et al:: Developing the atlas of cancer in Queensland: methodological issues. International Journal of Health Geographics 2011 10:9.

\section{Submit your next manuscript to BioMed Central and take full advantage of:}

- Convenient online submission

- Thorough peer review

- No space constraints or color figure charges

- Immediate publication on acceptance

- Inclusion in PubMed, CAS, Scopus and Google Scholar

- Research which is freely available for redistribution

Submit your manuscript at www.biomedcentral.com/submit
Ciomed Central 